\title{
Sarcopenia in elderly hospitalized coronary patients
}

\author{
Sarcopenia en pacientes coronarios hospitalizados
}

\section{RESUMEN}

La sarcopenia se define como un síndrome caracterizado por una pérdida progresiva y generalizada de la masa muscular y la fuerza del esqueleto, con un riesgo de resultados adversos como la discapacidad, la reducción de la calidad de vida y de muerte. Objetivo: Investigar la prevalencia de sarcopenia y sus factores asociados en pacientes cardíacos Métodos: Se realizó un estudio transversal en el hospital público del noreste de Brasil, en el que participaron pacientes mayores de 60 años con enfermedad coronaria. La sarcopenia fue determinada por la masa muscular (análisis de impedancia bioeléctrica y ecuación predictiva para determinar el índice de masa muscular esquelético), la fuerza muscular (medida por la fuerza de agarre) y el rendimiento físico (prueba de velocidad de conducción). Entre la asociación de variables se consideraron aspectos socioeconómicos, demográficos, clínicos, nutricionales y de estilo de vida. Resultados: Fueron

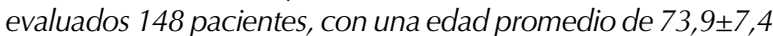
años. Se observó una prevalencia de sarcopenia del 62,8\%; incluyendo un $72 \%$ clasificado como severamente sarcopénico. Las variables asociadas a sarcopenia fueron sexo masculino $(p=0,014)$, edad $>80$ años $(p=0,005)$ y desnutrida según IMC ( $p<0,001), C B(p=0,006)$ y CP $(p=0,045)$; las otras variables no fueron estadísticamente significativas. Conclusión: La prevalencia de sarcopenia fue mayor, se encontró en una asociación con el género, un aumento en la edad, y el estado nutricional desfavorable.

Palabras clave: Ancianos; Sarcopenia; Enfermedad cardiovascular; Desnutrición.

\footnotetext{
ABSTRACT

Sarcopenia is a syndrome characterized by the progressive and widespread loss of skeletal muscle mass and strength, with a risk of adverse outcomes such as disability, reduced quality of life and death. Objective: To investigate the prevalence of sarcopenia and its associated factors in cardiac patients. Methods: We performed a cross-sectional study in a public hospital in northeast Brazil, involving patients aged $\geq 60$ years with coronary artery disease. Sarcopenia was determined by muscle mass (bioelectrical impedance analysis) and skeletal muscle mass index by a predictive equation, muscle strength
}

Roberta Maria Lins Mendes' ${ }^{1}$, Cláudia Porto Sabino Pinho ${ }^{1}$, Natália de Moraes Santana ${ }^{1}$, Natália Fernandes dos Santos ${ }^{1}$.

1. Pronto Socorro Cardiológico Universitário de Pernambuco

Corresponding author: Cláudia Porto Sabino Pinho. Rua Dos Palmares, $s / n^{\circ}$. Santo Amaro. Recife-PE, Brasil. Zip code: 50100060. E-mail: claudiasabinopinho@hotmail.com

Este trabajo fue recibido el 21 de agosto de 2017. Aceptado con modificaciones: 16 de junio de 2018. Aceptado para ser publicado: 08 de agosto de 2018.

(measured by grip strength) and physical performance (driving speed test). We tested relationships between sarcopenia and socioeconomic, demographic, clinical, nutritional and lifestyle variables. Results: We evaluated 148 patients, with an average age of $73.9 \pm 7.4$ years. We observed a prevalence of sarcopenia of $62.8 \%$; of which $72 \%$ were classified as having severe sarcopenia. The variables associated with sarcopenia were male sex $(p=0.014)$, age $>80$ years $(p=0.005)$, and being malnourished according to BMI $(p<0.001)$, arm circumference $(p=0.006)$ and calf circumference $(p=0.045)$; the other variables were not statistically significant. Conclusion: The prevalence of sarcopenia in our sample was high. We found that sarcopenia related to sex, age, and nutritional status. Keywords: Elderly; Sarcopenia; Cardiovascular disease; Malnutrition. 


\section{INTRODUCTION}

Aging is characterized by a continuous process in which changes occur in the various physiological systems. Among these changes, we highlight morphological changes, mainly related to changes in body composition, reduced functional capacity and the consequent impact on the quality of life of older people'.

Sarcopenia is a syndrome characterized by the progressive and widespread loss of skeletal muscle mass and strength, with a risk of adverse outcomes such as disability, reduced quality of life and death ${ }^{2}$. Although not restricted to older people, it is more prevalent in old age and increases with age ${ }^{3}$.

Unlike previous definitions of sarcopenia that focus on measurements of small muscle mass only, the European Working Group on Sarcopenia in Older People (EWGSOP) proposed that the diagnosis of sarcopenia should include the reduction of muscle mass associated with reduced strength or functionality, justifying that muscular strength depends not only on muscle mass. Thus, previous definitions of sarcopenia that only adopt the evaluation of muscle mass would be insufficient and with a limited clinical value ${ }^{2}$.

Several mechanisms may be involved in the development and progression of sarcopenia. One mechanism may relate to inherent changes in aging, such as the loss of units of motor neurons, decreased hormonal status (decline in serum levels of testosterone and growth hormone), physical inactivity, inadequate diet (low intake of protein, energy and vitamin D) and decreased insulin sensitivity. These changes lead to increased proteolysis, decreases in muscle protein synthesis and increased muscle fat infiltration. Furthermore, many diseases lead to prolonged rest and the use of numerous drugs, factors which may contribute to sarcopenia ${ }^{2,3}$.

Few studies estimate the prevalence of sarcopenia using the new multidimensional criteria proposed by the EWGSOP $2,3,4,5,6,7$, moreover, there are still scarce data about the magnitude of sarcopenia in some populations, like cardiac patients.

The association between sarcopenia and CVD risk is not well established. However, studies have shown that small muscle mass is associated with arterial stiffness, which is an independent predictor of cardiovascular disease (CVD). Sarcopenia may also affect the atherogenesis process due to the relative increase in secondary adipose tissue, muscle loss and replacement of myocytes by adipocytes ${ }^{8,9}$. In addition, when sarcopenia and obesity co-occur, there is a synergy which may result in muscle loss and dysfunction related to a pathological accumulation of adipose tissue. This condition is defined as sarcopenic obesity ${ }^{10}$.

This study aimed to evaluate the prevalence of sarcopenia and its correlates in coronary patients. Second, we verified the performance of risk instruments and nutritional assessment in the diagnosis of sarcopenia.

\section{METHODS \\ Design and study population}

We conducted a cross-sectional study in a public referral hospital for cardiology in northeast Brazil from april to july 2015. We recruited patients of both sexes, aged $\geq 60$ years, who were admitted to the coronary artery disease ward. Patients with physical and cognitive limitations, who were bedridden after cardiac surgery, with kidney disease on dialysis, who had edema and changes in the joints of the arms or legs that made it impossible to carry out the proposed tests were excluded.

To calculate the sample size, it was considered some internment of 250 seniors in the same period the year before the data collection. In a previous study of elderly hospitalized patients ${ }^{11}$, a prevalence of sarcopenia of $27.5 \%$ was found. Thus, using a standard error of $5 \%$ we calculated a sample size of 138 individuals. To adjust for potential loss of information we inflated our calculation by $10 \%$, for a total of 152 patients to be evaluated.

Data were collected after approval by the Ethics Committee for Research involving human subjects under protocol number 980360 - 03/25/2015.

\section{Sarcopenia}

Data were collected within 72 hours of admission to the ward by evaluators trained in the study protocol. Sarcopenia was identified, as proposed by EWGSOP2 ${ }^{2}$, from the evaluation of the following components: muscle mass, muscle strength and physical performance. Severe sarcopenia was defined as having all three criteria: reduction of mass, muscle strength and lower physical performance. Pre-sarcopenia was coded when non-sarcopenic individuals showed unfavorable results in the evaluation of lean body mass, the condition before sarcopenia.

Muscle mass was assessed with the skeletal muscle mass index (SMMI) obtained by the equation: $\mathrm{SMMI}=$ skeletal muscle mass (SMM) / height. The SMM, on the other hand, was calculated according to Jansen et $\mathrm{al},{ }^{30}: \mathrm{SMM}(\mathrm{kg})=[$ (Height $(\mathrm{cm})^{2} /$ Resistance $\left.(\mathrm{ohm}) \times 0.401\right)+(3.825 \times$ Sex $($ male $=1$ and women $=0))+(-0.071 \times$ Age in years) $]+5,102)$. The resistance measurement used in the equation was obtained from bioelectrical impedance analysis (BIA), using the portable Biodynamics model 310, which applies an electrical current of $800 \mathrm{uA}$ with a single frequency of $50 \mathrm{kHz}$, according to the methodology proposed by Kyle et $\mathrm{a}^{12}$. We used the cutoff point for SMMI from the National Health and Nutrition Examination Survey $(\mathrm{NHANES} \mathrm{III)})^{13}$, which set a small muscle mass for the elderly as $\mathrm{SMMl}<6.76 \mathrm{~kg} / \mathrm{m}^{2}$ for women and $<10.76 \mathrm{~kg} / \mathrm{m}^{2}$ for $\mathrm{men}^{2}$.

Muscle strength, measured by hand grip, was obtained in triplicate using a Jamar dynamometer and a previously established technique ${ }^{14}$. Values $<30 \mathrm{~kg} / \mathrm{f}$ and $<20 \mathrm{~kg} / \mathrm{f}$ for men and women, respectively, were considered unfavorable per EWGSOP${ }^{2}$. For the assessment of physical performance the gait speed test was conducted in duplicate. This test involves walking a distance of 4 meters on a flat surface, with $<0.8$ meters/second being considered slow speed ${ }^{15}$.

Sarcopenic obesity was diagnosed when the individual 
had a waist circumference $\geq 88 \mathrm{~cm}$ for women and $\geq 102$ $\mathrm{cm}$ for men, along with the diagnosis of sarcopenia ${ }^{16}$. Waist circumference was measured with a tape measure in duplicate at the midpoint between the last rib and the iliac crest; the reading performed at the end of the intervention ${ }^{17}$.

\section{Socio-demographic, clinical, nutritional and lifestyle variables}

Clinical and demographic data was collected from interviews with the patients or obtained from clinical records. We collected information on age, sex, race and education (years of study). The race/color was determined by the interviewer and classified as white, brown or black18. We considered whether participants had diabetes mellitus (DM), hypertension, or anemia. We assessed inflammatory status using C-Reactive Protein (CRP) $)^{19}$.

The variables used for the evaluation of the lifestyle were physical activity, evaluated according to the criteria of the American College of Sports Medicine ${ }^{20}$, which classifies individuals as sedentary, intermediate and active, and smoking (smoker, non-smoker and former smoker).

The following anthropometric variables were assessed: body mass index (BMI), with established classification according to cutoff point for seniors proposed by Lipschitz [26], arm circumference (AC) and calf circumference (CC). For AC, we measured the left arm at the midpoint between the acromion of the scapula and the olecranon of the ulna. The midpoint was determined with the arm flexed at $90^{\circ}$, yet AC obtained with the arm relaxed. The results were compared with reference values provided by the National Health and Nutrition Examination Survey - NHANES III ${ }^{11}$, and classified as proposed by Blackburn and Thornton ${ }^{22}$. For CC, the measurement was made at the highest volume of the calf and is considered reduced when $\mathrm{CC}<31 \mathrm{~cm}^{2}$. Nutritional risk was assessed using the Nutritional Risk Screening $(\mathrm{NRS})^{23}$; dietary risk was coded as a NRS score was greater than or equal to 3 .

\section{Statistical analysis}

The tabulation and analysis of data were carried out with the help of SPSS version 13.0 (SPSS Inc., Chicago, IL, USA). We performed a descriptive analysis of the variables by calculating the frequency distributions and measures of central tendency. Continuous variables were tested according to the standard distribution by the Kolmogorov-Smirnov test and in samples with normal distribution we used the average and standard deviation. The association among categorical variables was analyzed using the Pearson chi-square test. The significance level for all tests was less than 0.05. The performance of nutritional parameters (anthropometry and risk screening) as risk markers of sarcopenia was assessed using the Kappa index, sensitivity, specificity, and accuracy.

\section{RESULTS}

During the period of study, 219 elderly were admitted; 48 did not meet the eligibility criteria ( 2 had edema, 10 due to amputation of limbs, 14 to total bed rest, 11 were on dialysis and 11 were in the immediate postoperative period). In addition, 1 person refused participation, 13 were discharged, and 9 had data inconsistencies. Thus, we concluded with a sample of 148 subjects, whose average age was $71.6( \pm 7.6)$ years and the most common age group was 60-69 years $(43.2 \%)$. There was homogeneous distribution between the sexes, the predominance of brown breed (46.6\%) and low education (92.6\%). About $80 \%$ of patients had been diagnosed with acute myocardial infarction or angina, and hypertension and DM prevalence were $90.5 \%$ and $45.9 \%$, respectively (Table 1 ).

Table 1. Sociodemographic, clinical and behavioral characteristics of elderly coronary patients admitted to a cardiology hospital in Northeast Brazil ( $\mathrm{N}=148)$.

\begin{tabular}{|c|c|c|}
\hline Variable & $\mathbf{n}$ & $\%$ \\
\hline \multicolumn{3}{|l|}{ Sex } \\
\hline Male & 76 & 51.4 \\
\hline Female & 72 & 48.6 \\
\hline \multicolumn{3}{|l|}{ Age group (years) } \\
\hline $60-69$ & 64 & 43.2 \\
\hline $70-79$ & 61 & 41.2 \\
\hline$\geq 80$ & 23 & 15.5 \\
\hline \multicolumn{3}{|l|}{ Race } \\
\hline White & 45 & 30.4 \\
\hline Brown & 69 & 46.6 \\
\hline Black & 34 & 23.0 \\
\hline \multicolumn{3}{|l|}{ Civil status } \\
\hline Married/Stable & 77 & 52.0 \\
\hline Single & 27 & 18.2 \\
\hline Divorced & 11 & 7.4 \\
\hline Widower/Widow & 33 & 22.3 \\
\hline \multicolumn{3}{|l|}{ Schooling (years completed) } \\
\hline$\leq 9$ & 137 & 92.6 \\
\hline$>9$ & 11 & 7.4 \\
\hline \multicolumn{3}{|l|}{ Smoking } \\
\hline Smoker & 22 & 14.9 \\
\hline Non-smoker & 104 & 70.3 \\
\hline Ex-smoker & 22 & 14.9 \\
\hline \multicolumn{3}{|l|}{ Physical activity } \\
\hline Active & 07 & 4.7 \\
\hline Intermediate & 28 & 18.9 \\
\hline Sedentary & 113 & 68.7 \\
\hline Hypertension & 134 & 90.5 \\
\hline Diabetes Mellitus & 68 & 45.9 \\
\hline \multicolumn{3}{|l|}{ Clinical Diagnosis } \\
\hline Acute myocardial infarction or angina & 115 & 77.7 \\
\hline Others & 33 & 22.3 \\
\hline \multicolumn{3}{|l|}{ CRP } \\
\hline Average & 42 & 31.3 \\
\hline Elevated & 92 & 68.7 \\
\hline Anemia & 70 & 47.3 \\
\hline
\end{tabular}

CRP, C-Reactive Protein. 
According to the nutritional screening, $34.9 \%$ of subjects had nutritional risk. The prevalence of malnutrition according to $\mathrm{AC}$ and $\mathrm{CC}$ were $25.7 \%$ and $25.0 \%$ respectively. The $\mathrm{BMI}$ average was $26.6 \pm 4.3 \mathrm{~kg} / \mathrm{m}^{2}$, with a high prevalence of overweight (39.2\%). Higher prevalence of malnutrition according to AC was found in males $(p=0.028)$ and according to $C C$, in females $(p=0.001)$ (Table 2$)$.

The prevalence of sarcopenia was $62.8 \%$, and individuals were mostly classified as severely sarcopenic $(72 \%)$. Evaluating the criteria for the definition of sarcopenia, $34.5 \%$ had reduced handgrip strength; $81.8 \%$ slow gait and $75.0 \%$ low skeletal muscle mass index. Among nonsarcopenic individuals, $29 \%$ had pre-sarcopenia, which was more prevalent in men $(p<0.001)$. The impairment of hand grip strength was similar in men and women, but low gait function was higher in females $(p=0.027)$ and reduced skeletal muscle mass was more prevalent in males (Table 3).

Among the variables analyzed, the presence of sarcopenia was associated with sex, being more prevalent among men $(p=0.014)$, among individuals with advanced age $(p=$ $0.005)$, and malnourished, according to the anthropometric parameters assessed $(p<0.05)$. The other variables associated with sarcopenia are described in Table 4.

We found low performance of diagnostic parameters and nutritional risk screening as markers of sarcopenia: low sensitivity, concordance and accuracy. Only high specificity was observed, varying from $72.7 \%$ to $94.5 \%$, indicating the markers can be useful to determine the absence of sarcopenia, but not its presence (Table 5).

\section{DISCUSSION}

The aging of the population has aroused great interest as it is a phase of life in which health-related injuries usually occur with impairment of the autonomy of the elderly. It has been suggested that sarcopenia be regarded as a "geriatric syndrome," a term for describing a complex, but common clinical situation observed in old age that does not fall into any category of disease (e.g. falls, weakness, delirium, and incontinence, among others $)^{24}$. The literature provides few studies evaluating sarcopenia in the hospital environment ${ }^{3,9}$. Therefore, this research aimed to assess the prevalence of sarcopenia in hospitalized coronary heart disease patients using the criteria proposed by EWGSOP, which includes measures of muscle mass, strength and physical performance applied to clinical practice ${ }^{2}$.

CVDs, including ischemic heart disease (the main reason for hospitalization of the study population), are the leading causes of death worldwide and have the greatest impact in low and middle-income countries. In Brazil, even with a reduction in mortality, CVD accounted for $31.2 \%$ of

Table 2. Nutritional and anthropometric classification of elderly coronary patients admitted to a cardiology hospital in Northeast Brazil $(\mathrm{n}=148)$.

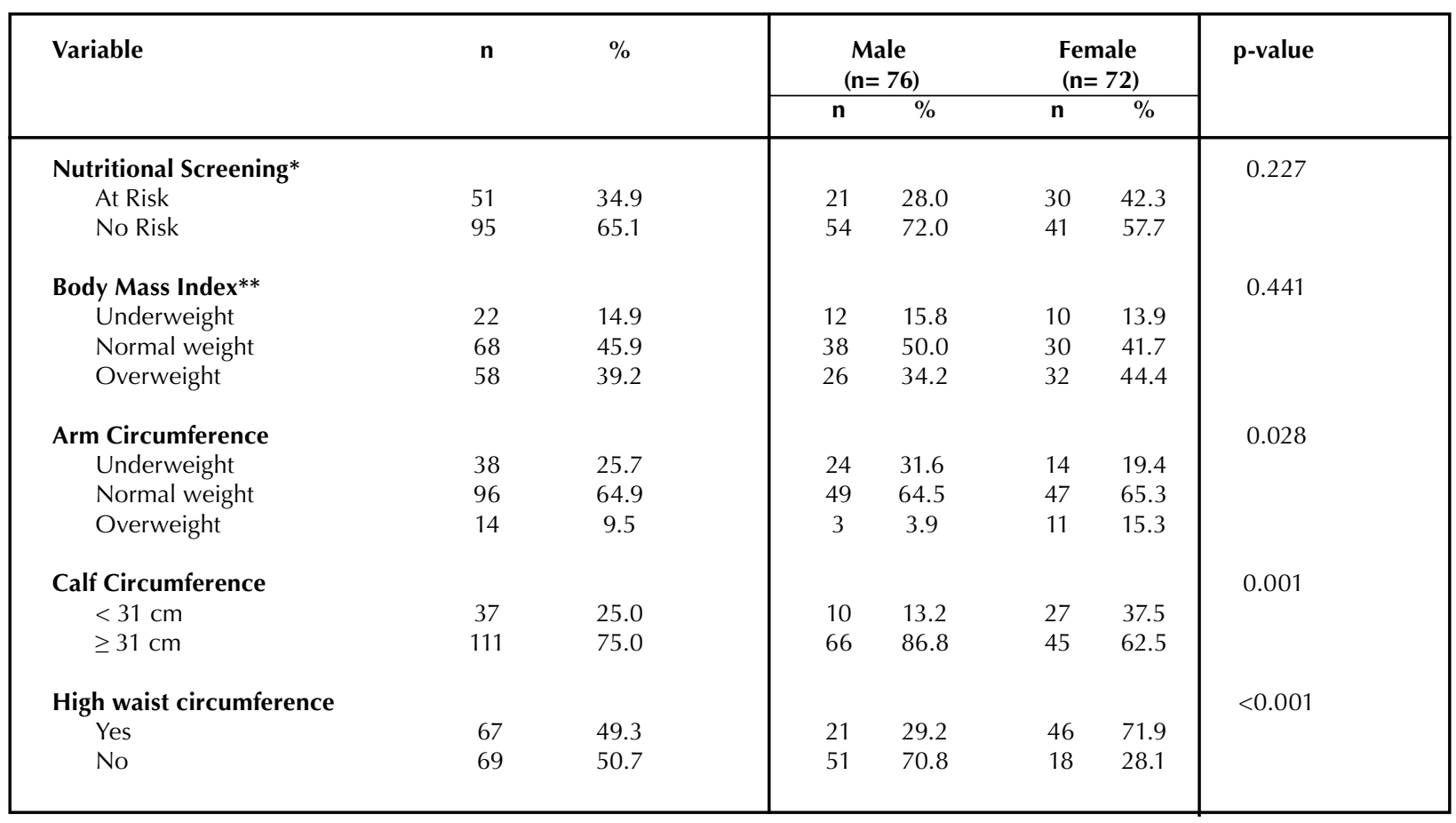

*NRS, 2002; **Lipschitz,1994 
Table 3. Prevalence and classification of sarcopenia; a predominance of sarcopenic obesity and changes to the criteria involved in the diagnosis of sarcopenia in the elderly coronary patients admitted to the cardiology hospital.

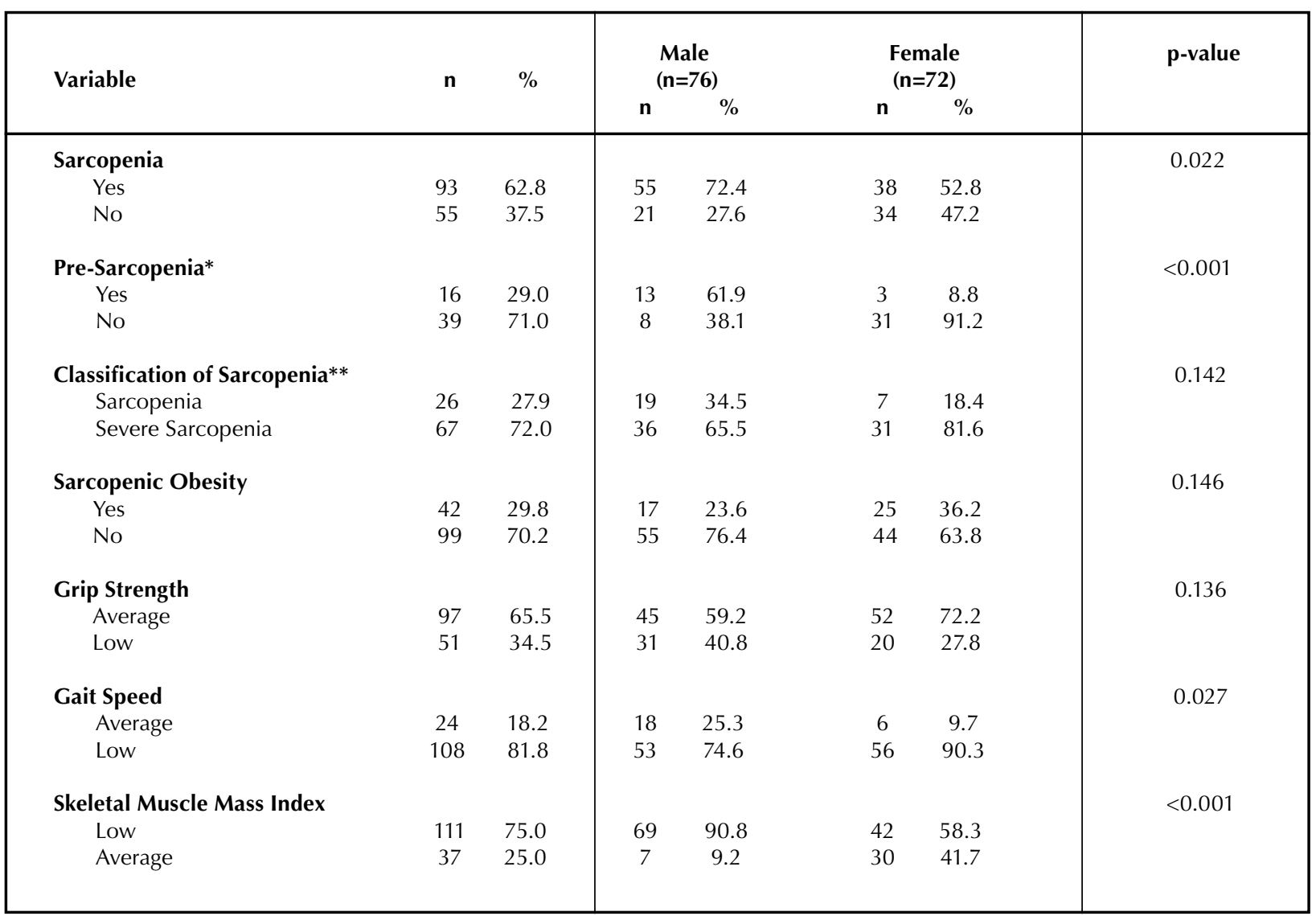

*Among non-sarcopenic individuals; **Among sarcopenic individuals.

deaths in 2010 and $27.4 \%$ of hospitalizations in people over 60 years of age. There is a paucity of literature investigating the occurrence of sarcopenia in these patients ${ }^{25,26}$.

The prevalence of nutritional risk (34.9\%) and malnutrition (varying from $14.9 \%$ to $25.7 \%$, depending on anthropometric parameter) observed in this study was less than the national rate among hospitalized elderly Brazilians. The BRAINS survey (Brazilian Investigation of Nutritional Status in hospitalized patients ${ }^{27}$, a multicentric research study that included a sample of 10,234 seniors and used MAN (Mini Nutritional Assessment) as a tool for evaluation, reported a prevalence for risk of malnutrition of $69.2 \%$ and $38.4 \%$ for undernourishment.

Hospital malnutrition relates to higher incidence of complications and mortality, longer hospitalization, increased costs to the health service, delayed recovery, frequent hospital readmissions and reduced quality of life ${ }^{27}$. Although this study involved a population homogeneous with respect to clinical condition, data on the nutritional status mirrors results for elderly patients hospitalized for various clinical diagnoses.

The high prevalence of sarcopenia observed in this study $(62.8 \%)$ is a worrying finding considering the impact of this condition on the quality of life of the elderly. Among the effects of sarcopenia include the reduction of mobility and functional capacity, increased fragility, increased risk of falls and fractures, as well as greater dependency, hospitalizations, and risk of death ${ }^{28}$.

Data on the magnitude of sarcopenia vary in the literature and depend on the characteristics of the sample (where individuals were sampled from, the ethnic composition of the population and underlying pathologies and the method selected for its definition. Chavez-Moreno et al. ${ }^{9}$, in a study conducted in Mexico, used the predictive equation for obtaining the appendicular skeletal muscle mass, grip strength and a functionality index for the performance of essential daily living activities to classify sarcopenia and found a prevalence of $27.5 \%$ of sarcopenia in hospitalized elderly patients, regardless of reason for hospitalization. In a recent study by Gariballa and Alessa ${ }^{29}$, which aimed to study sarcopenia in elderly hospitalized patients revealed a prevalence of $10 \%$. However, authors only evaluated muscle mass and handgrip strength, and not physical performance as suggested by EWGSOP criteria. 
Table 4. Associations between sarcopenia and sociodemographic, clinical, behavioral and nutritional status of elderly coronary patients admitted to a cardiology hospital.

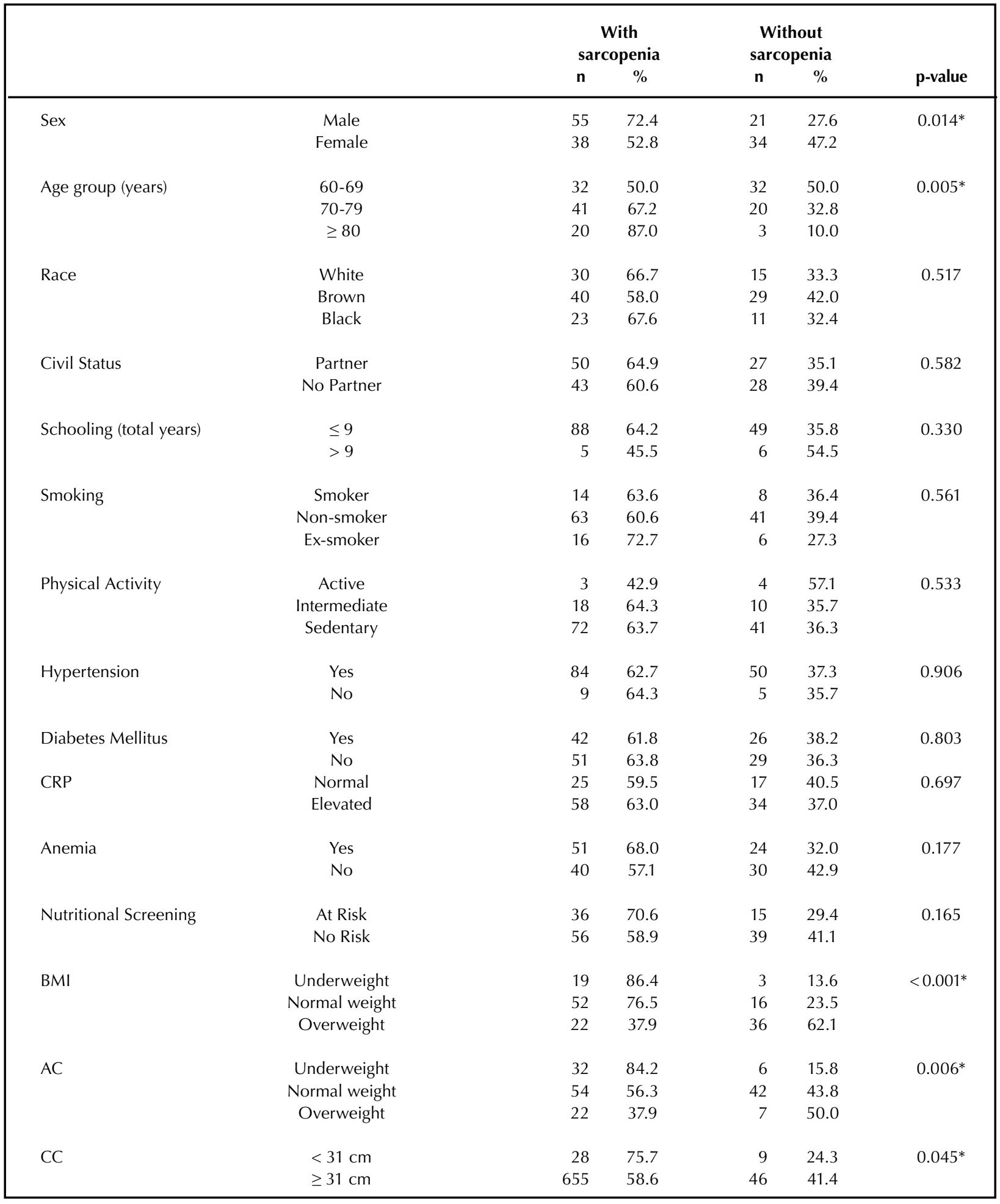

${ }^{*} \mathrm{w}<0.05$; Hypertension, systemic hypertension; CRP, C-reactive protein; BMI, body mass index; AC, arm circumference; CC, calf circumference. 
Table 5. Sensitivity, specificity, consistency and accuracy of the assessment parameters and nutritional risk in diagnosing sarcopenia compared to the skeletal muscle index.

\begin{tabular}{|lcccc|}
\hline & BMI & AC & CC & NRS \\
\hline Sensitivity (\%) & 20.4 & 34.4 & 30.1 & 38.7 \\
Specificity (\%) & 94.5 & 89.1 & 83.6 & 72.7 \\
Kappa (\%) & 12.0 & 20.0 & 11.0 & 10.0 \\
Accuracy(\%) & 48.0 & 54.7 & 50.0 & 51.4 \\
& & & & \\
\hline
\end{tabular}

BMI, Body Mass Index; CB, Arm Circumference; CP, Calf Circumference; NRS, Nutritional Risk Screening

A study conducted by Patel et al. ${ }^{4}$, applied the EWGSOP criteria and found a prevalence of $7.8 \%$ sarcopenia in a sample of 1,787 elderly community residents in the UK, whose fat-free mass was assessed using anthropometry. However, in a small subsample of 103 men, in which lean body weight was determined by Dual Energy X-ray Absorptiometry (DEXA) a prevalence of $6.8 \%$ was found. Another study considered only skeletal muscle mass assessed by BIA and DEXA and found a prevalence of sarcopenia of $70.7 \%$ in men and $41.9 \%$ in women ${ }^{30}$.

We observed that $72.0 \%$ of sarcopenic participants had severe sarcopenia (unfavorable condition for the three diagnostic criteria: mass, strength, and function) and among non-sarcopenic participants, $29.0 \%$ had pre-sarcopenia (reduced muscle mass only). These data are different than previous findings of other authors. In a study conducted in a German hospital using the same criteria adopted in this research, Smoliner et al. ${ }^{3}$ identified that $25.3 \%$ of patients had sarcopenia, among which $18.7 \%$ had severe sarcopenia. In another study evaluating elderly persons seen in a geriatric outpatient clinic of a university hospital in northeast Brazil, the prevalence of sarcopenia was $18 \%$ and among these sarcopenic individuals, $66.7 \%$ had severe sarcopenia ${ }^{5}$.

The high percentage of severe sarcopenia may be attributed to the fact that the sample involved hospitalized cardiac patients. The cross-sectional design of this study does not infer cause and effect. However, as recent evidence has indicated, sarcopenia can be an independent predictor of cardiovascular disease. Sarcopenia is associated with arterial stiffness, the relative increase in fat tissue and replacement myocyte by adipocytes 7 . Thus, it is possible that these cardiac patients are often more at risk than patients without sarcopenia. Moreover, our study was conducted in a public hospital and the individuals had a high percentage of low educational level $(92.6 \%$ with less than nine years of schooling), it can be assumed that participants were low-income. This may compromise access to a healthy diet from a qualitative and quantitative point of view.

A significant percentage of patients had sarcopenic obesity (29.8\%). Its classification has a topic of controversy in the literature and there is still no consensus for such an assessment. Therefore, it is difficult to carry out a comparative analysis with previously published data. Atkin et al. ${ }^{8}$ report that together, sarcopenia and obesity may increase the magnitude of effects on metabolic diseases, cardiovascular diseases and mortality rates as compared with obesity or sarcopenia alone.

Among the procedures adopted for diagnosis of sarcopenia, slow gait speed (which predicts functionality) showed the worst result $(81.8 \%$ slow gait speed). A wide variety of tests are available for the assessment of physical performance. However, gait speed is considered a secure and reliable indicator for the screening of functional capacity, which can be used in clinical and research environments capable of reflecting the risk of adverse outcomes related to the health of the elderly $y^{2,14}$.

Hand grip, which has been widely used and considered one of the validated techniques to measure muscle strength, was the criterion was the criterion least related to sarcopenia $(34.5 \%)$ in this research. A weak hand grip is a clinical marker of reduced mobility which has been associated with mortality in patients with advanced age and can be a reliable substitute for more sophisticated measures of muscle strength in the upper limbs, which also correlates with leg force ${ }^{2}$. In a 24-year longitudinal study, Gale et al. ${ }^{31}$ observed that hand grip was a predictor of long-term mortality from cardiovascular disease and cancer in men.

The higher prevalence of sarcopenia in males corroborates evidence that has demonstrated a more pronounced decrease in muscle mass and strength in men compared to women. Janssen et al. ${ }^{32}$ reported a prevalence of sarcopenia 31\% among elderly females and $64 \%$ among males. Men tend to have more muscle loss due to the decline of growth hormone, growth factor related to insulin (IGF-1) and testosterone; also, they have worse adaptation to muscle loss than women ${ }^{33}$.

The increased prevalence of sarcopenia pari passu with the progression of age observed in this study has been reported in previously published data ${ }^{5,33}$. It is known that age is a determining factor for the occurrence of sarcopenia. In addition, there is an increase in prevalence with each decade of life, as shown by Leite et al. ${ }^{33}$, who reported a prevalence between $13 \%$ and $24 \%$ for ages $65-70$ years and over $50 \%$ for those over 80 .

Although we did not observe an association between sarcopenia and race in this investigation some have found higher muscle mass values for persons of African descent group compared to Caucasians and Asians ${ }^{34}$. Delmonico et al. ${ }^{35}$ reported the prevalence of sarcopenia among white men and women was $25.2 \%$ and $31.4 \%$, respectively, and for blacks, $11.8 \%$ and $6.8 \%$, respectively. The lower prevalence of sarcopenia in persons of African descent has been attributed to different amounts of lean mass and a greater amount of skeletal muscle. Mainly due to genetic factors, this group has higher testosterone compared to whites and thus may be more protected from tissue reduction that accompanies aging ${ }^{36}$. 
Despite not having been identified to be associated with sarcopenia in the current study, one of the primary causes of this condition is the lack of physical activity. Kortebein et al. ${ }^{37}$, demonstrated that the effect of 10 days of rest in healthy elderly individuals resulted in a loss of $3 \%$ in fat-free mass and $15 \%$ muscle strength. Physical exercise, especially resistance training, has been indicated as the most effective strategy to prevent and reverse sarcopenia, with benefits for strength and muscle mass ${ }^{38}$.

The metabolic effects of sarcopenia include lower resting energy expenditure, reduced fat oxidation, increased insulin resistance, and higher predisposition to DM, dyslipidemia and hypertension ${ }^{3,4}$. However, in this study, no association with sarcopenia was found with these conditions.

The literature suggests that inflammation may also relate to sarcopenia. Cesari et al. ${ }^{39}$, showed that CRP and Interleukin-6 were inversely associated with fat-free mass. In this study, no association was observed between the prevalence of sarcopenia and inflammation, possibly because all individuals were hospitalized due to a coronary event. We measured CRP, which is a non-specific marker of inflammation and can be altered by many clinical situations. Thus, it is likely that in this circumstance, its alteration was more associated with other causes besides sarcopenia. This relationship should be further investigated in healthy subjects.

Malnutrition, assessed by anthropometric parameters (BMI, AC, and CC), was significantly associated with sarcopenia. Smoliner et al. ${ }^{3}$, on the other hand, observed that $53 \%$ of patients identified as malnourished or at nutritional risk were not considered sarcopenic. Although malnourished individuals are more likely to develop the condition of sarcopenia, given that the causative factors of both are similar and sometimes interrelated, it is important to emphasize that sarcopenia is a condition that involves other aspects in addition to mass muscle like strength and functionality.

Sarcopenia is still poorly assessed in clinical practice; equipment to measure sarcopenia is often unavailable and the test is difficult for elderly patients. Thus, the performance of easily obtained anthropometric parameters (BMI, CB and $\mathrm{CC}$ ) and a nutritional risk score (NRS) as a marker of sarcopenia were tested, however, it was verified that these variables presented low sensitivity, agreement and accuracy. This finding reinforces the multidimensionality of sarcopenia, showing that diagnostic markers or nutritional risk measurements alone are not sufficient to predict the breadth of this condition, which includes functionality, muscle mass and strength. Therefore, anthropometry is limited and should not be used alone in the nutritional assessment of the elderly.

Some limitations must be considered when interpreting the data presented. The cross-sectional design of this study is a restriction in the analysis of causal relations between exposure variables and sarcopenia. Additionally, participants in the study were obtained from a reference hospital for cardiology. Therefore, the extrapolation of findings for other older individuals should be carried out with caution. Another limitation was that diet, which is critical to muscle preservation, was not assessed. However, since we conducted a hospital-based study, dietary intake may vary compared to eating habits of other populations of older individuals. In addition, as the study was conducted with an elderly population, it must be mentioned that memory difficulties may make an accurate dietary accounting difficult.

The prevalence of sarcopenia was high in our sample, with higher rates in males, elderly patients with advanced age and underweight--o. Anthropometric parameters and nutritional risk screening were not useful markers for identification of sarcopenia. Considering the lack of research on the problem of sarcopenia in cardiac patients and the significant prevalence in these patients, this study contributes to building greater awareness among health professionals regarding the importance of evaluating, monitoring and preventing this condition to establish strategies to treat these patients and offer them better-living conditions. Moreover, it is important that other studies be developed in different populations so that a consensus can be reached on the characteristics of individuals with higher risk for sarcopenia. Also, prospective studies would be useful for elucidating the role of sarcopenia as a marker of cardiovascular risk.

Financial support: Self-financed.

Conflict of interest: None.

\section{REFERENCES}

1. Augustemak de Lima $L R$, Rech CR, Petroski EL. Use of bioelectrical impedance for the estimation of skeletal muscle mass in elderly men. Arch Latinoam Nutr 2008; 58(4): 386391.

2. Cruz-Jentoft AJ, Baeyens JP, Bauer JM, Boirie $Y$, Cederholm $T$, Landi F, et al. Sarcopenia: European consensus on definition and diagnosis: Report of the European Working Group on Sarcopenia in Older People. Age Ageing 2010; 39(4): 412423.

3. Smoliner C, Sieber CC, Wirt R. Prevalence of Sarcopenia in Geriatric Hospitalized Patients. JAMDA 2014; 15: 267-272.

4. Patel HP, Syddall HE, Jameson K, Robinson S, Denison $\mathrm{H}$, Roberts $\mathrm{HC}$, et al. Prevalence of sarcopenia in community dwelling older people in the UK using the European Working Group on Sarcopenia in Older People (EWGSOP) definition: findings from the Hertfordshire Cohort Study (HCS). Age Ageing 2013; 42: 378-384.

5. Almeida dos Santos AD, Pinho CPS, Nascimento ACS, Costa ACO. Sarcopenia in elderly outpatients: prevalence and associated factors. Nut Hosp 2015; 32(2): 255-262.

6. Lera et al. Prevalence of sarcopenia in community-dwelling Chilean elders according to an adapted version of the European Working Group on Sarcopenia in Older People (EWGSOP) criteria. The Journal of Frailty \& Aging 2017; 6(1): 12-17.

7. Wu CH, Chen KT, Hou MT, et al. Prevalence and associated factors of sarcopenia and severe sarcopenia in older Taiwanese living in rural community: The Tianliao Old People study 04. Geriatr Gerontol Int 2014; 14: 69-75.

8. Freitas WM, Carvalho LSF, Moura FA, Sposito AC. Atherosclerotic disease in octogenarians: A challenge for science and clinical 
practice. Atherosclerosis 2012; 225: 281-289.

9. Kim TN, Choi KM.The Implications of Sarcopenia and Sarcopenic Obesity on Cardiometabolic Disease. J Cell Biochem 2015; 116: 1171-1178.

10. Atkin JL, Whincup PH, Morris RW, Wannamethee SG. Low muscle mass in older men: The role of lifestyle, diet and cardiovascuLar risk factors. JNHA 2014, 18(1):26-33.

11. Chavez-Moreno DV, Infante-Sierra $H$, Serralde-Zuniga AE. Sarcopenia and funcionality in elderly inpatient. Nutr Hosp 2015; 31(4): 1660-1666.

12. Kyle UG, Bosaeus I, De Lorenzo AD, Deurenberg P, Elia M, Gómez JM, et al. Bioelectrical impedance analysis-part I: review of principles and methods. Clin Nutr 2004; 23(5): 1226-1243.

13. Nhanes: Kuczmarski MF; Kuczmarski RJ; Najjar M. Descripitive anthropometric reference data for older Americans. J Am Diet Assoc 2000; 100: 59-66.

14. Fess EE. Grip strength. In: Casanova JS, editor. Clinical Assessment Recommendations. 2nd ed. Chicago: Am Soc Hand Therapists 1994.

15. Van Kan GA,Rolland Y, Andrieu S, Bauer J, Beauchet O, Bonnefoy $M$ et al. Gait speed at usual pace as a predictor of adverse outcomes in communitydwelling older people - An Internationl Academy on Nutrition and Aging (IANA) Task Force. JNHA 2009; 13(10): 881-889.

16. Stenholm S. Harris, T.B., Rantanen, T., Visser, M., Kritchevsky, S.B. and Ferrucci, L. Sarcopenic obesity: definition, cause and consequences. Curr Opin Clin Nutr Metab Care 2009; 11: 693-700.

17. World Health Organization. Obesity: preventing and managing the global epidemic. Report of a WHO Consultation. Geneva: WHO Technical Report Series 894. World Health Organization, 1998.

18. Olinto MTA, Nacul LC, Dias-da-Costa JS, Gigante DP, Menezes $A M B$, Macedo S. Intervention levels for abdominal obesity: prevalence and associated factors. Cad Saúde Publica 2006; 22(6): 1207-1215.

19. Vasan RS, Sullivan LM, Roubenoff $R$, Dinarello CA, Harris $T$, Benjamin EJ, et al. Inflammatory Markers and Risk of Heart Failure in Elderly Subjects Without Prior Myocardial Infarction The Framingham Heart Study. Circulation 2003; 107: 14861491.

20. American College of Sports Medicine. Guidelines for exercise testing and prescriptions ( $4^{a}$ ed.). Filadélfia: Lea and Febiger. 1991.

21. Lipschitz DA. Screening for nutrition status in the elderly. Prim Care 1994; 21(1): 55-67.

22. Blackburn GL, Bistrian BR, Maini BS, Schlamm HT, Smith MF. Nutricional and metabolic assessment of the hospitalized paciente. J Parent Ent Nutr 1979; 1(1): 11-12.

23. Kondrup J, Allison SP, Elia M, Vellas B, Plauth M. ESPEN (European Society for Parenteral and Enteral Nutrition) guidelines for nutrition screening 2002. Clin Nutr 2003; 22(4): 415-421.

24. Mitchell WK, Williams J, Atherton P, Larvin M, Lund J, Narici M. Sarcopenia, dynapenia, and the impact of advancing age on human skeletal muscle size and strength; a quantitative review. Front Physiol 2012; 3(260): 1-18.

25. Mendis S, Puska P, Norrving B. World Health Organization. Global atlas on cardiovascular disease prevention and control. Geneva: WHO; 2011.

26. Schmidt MI, Duncan BB, Azevedo e Silva G, Menezes AM, Monteiro AM, Barreto, et al. Chronic non communicable diseases in Brazil: burden and current challenges. Lancet 2011; 377(9781): 1949-1961.

27. Borghi R, Meale MMS, Gouveia MAP, França IID, Damião AOMC. Nutritional status of hospitalized patients in Brazil: analysis of 19,222 patients (BRAINS Study). Rev Bras Nutr Clín 2013; 28(4): 255-263.

28. Silva TAA, Frisoli Junior A, Pinheiro MM, Szejnfeld VL. Sarcopenia and Aging: Etiological Aspects and Therapeutic Options. Rev Bras Reumatol 2006; 46(6): 391-397.

29. Gariballa S, Alessa A. Sarcopenia: Prevalence and prognostic significance in hospitalized patients. Clin Nutr 2013; 32: 772-776.

30. Janssen I, Heymsfield SB, Baumgartner RN, Ross R. Estimation of skeletal muscle mass by bioelectrical impedance analysis. J Appl Physiol 2000; 89: 465-471.

31. Gale C. R., Martyn, C. N., Cooper, C.; Sayer, A. Grip strength, body composition, and mortality. Int I Epidemiol 2007; 36(1): 228-235.

32. Janssen I, Baumgartner RN, Ross R, Rosenberg IH, Roubenoff R. Skeletal muscle cutpoints associated with elevated physical disability risk in older men and women. Am J Epidemiol 2004; 159(4): 413-421.

33. Leite LEA, Resende TL, Nogueira GM, Cruz IBM, Schneider RH, Gottlieb MGV. Aging, oxidative stress and sarcopenia: a systemic approach. Rev Bras Geriatr. Gerontol 2012; 15 (2): 3653-3680.

34. Wang Z, Heo M, Lee RC, Kotler, DP, Withers RT, Heymsfield $S B$. Muscularity in adult humans: proportion of adipose tissue-free body mass as skeletal muscle. Am J Hum Biol 2001; 13: 612-619.

35. Delmonico MJ, Harris TB, Lee JS, Visser $M$, Nevitt $M$, Kritchevsky $S B$, et al. Alternative definitions of sarcopenia, lower extremity performance, and functional impairment with aging in older men and women. J Am Geriatr Soc 2007; 55(5): 769-774.

36. Gerace LA, Aliprantis M, Russell DB, Allison KM, Buhl JW, Wang ZM, et al. Skeletal differences between black and white men and their relevance to body composition estimates. Am J Human Biol 1994; 6(2): 255-262.

37. Kortebein P, Ferrando A, Lombeida J, Wolfe R, Evans WJ. Effect of 10 days of bed rest on skeletal muscle in healthy older adults. JAMA 2007; 297(16): 1772-1774.

38. Li Z, Heber D. Sarcopenic obesity in the elderly and strategies for weight management. Nutr Rev 2011; 70(1): 57-64.

39. Cesari $M$, Kritchevsky SB, Baumgartner RN, Atkinson $H H$, Penninx B, Lenchik L, et al. Sarcopenia, obesity, and inflammation-results from the Trial of Angiotensin Converting Enzyme Inhibition and Novel Cardiovascular Risk Factors study. Am J Clin Nutr 2005; 82(2): 428-434. 